doi: $10.15407 /$ ujpe61.11.0973

B. ROMANYUK, ${ }^{1}$ V. MELNIK, ${ }^{1}$ V. POPOV ${ }^{1}$ O. KOROTCHENKOV ${ }^{2}$

${ }^{1}$ Lashkaryov Institute of Semiconductor Physics, Nat. Acad. of Sci. of Ukraine

(41, Prosp. Nauky, Kyiv 03028, Ukraine; e-mail: romb@isp.kiev.ua)

2 Faculty of Physics, Taras Shevchenko National University of Kyiv

(64/13, Volodymyrs'ka Str., Kyiv 01601, Ukraine)

\title{
STATIONARY MULTISTAR-SHAPE PATTERNS OF WATER DROPS IN THE PRESENCE PACS 47.55.D-, 47.55.dr OF A TEMPERATURE GRADIENT
}

\begin{abstract}
The evolution of a shape of liquid drops placed onto superheated surfaces has been of interest for several decades, since it is related to various phenomena ranging from atomic nuclear fission to planetary rotation and occurs in numerous industrial processes. We show that a drop locked in a spherical crevice displays multistar-shape patterns with unusually large number of stars $n$, which can be as high as eleven. The data are interpreted in terms of multiplicative shape disturbances of the drop, which are created by continuously repetitive gas overheats and vapor breakups. This process accompanied by pulsating motions of the drop ends up in a stationary $n$-star configuration. We also report on the freezing-like behavior of the drop evaporating in a sequence of freezing states. This discovery can be applied to the control over liquid-gas phase transitions at superheated surfaces and can be used for measuring the viscosity and the concentration of particles in suspensions.
\end{abstract}

Ke ywords: liquid drop, superheated surface, levitation, star configuration.

\section{Introduction}

It is frequently suspected that though the atoms in a liquid droplet are somewhat randomly arranged, they may actually be more stuck than they seem. So considering the surface tension- and surface impactcontrolled shapes of liquid drops is a part of the more general problem of treating the dynamics of rotating masses under gravitational, electric, or even nuclear forces. Because the large groups of atoms can cooperate to move together, amazing shapes can occur, where the bunches of atoms group together in an ordered formation. These shapes seem to interrupt the larger patterns, thus preventing the liquid from becoming a solid.

The behavior of fluids in confined geometries, in particular, in vicinities of solid substrates, is proving to be of real technological significance and is of considerable importance in numerous natural phenomena $[1,2]$. In particular, the evolution of the shape of a water drop rotated about a vertical axis or placed onto a superheated surface has been a subject of intensive studies for several decades [3-8], since it is related

(C) B. ROMANYUK, V. MELNIK, V. POPOV,

O. KOROTCHENKOV, 2016

ISSN 2071-0194. Ukr. J. Phys. 2016. Vol. 61, No. 11 to various phenomena ranging from atomic nuclear fission to planetary rotation and occurs in numerous industrial processes.

When the drop is placed on a surface heated above some critical temperature, the water may evaporate so rapidly that the drop floats on its own vapor layer (Leidenfrost regime) with a thickness of about $100 \mu \mathrm{m}$ [9]. There are four distinct regimes of the heat transfer between the substrate and the drop [10]. In the single-phase regime characterized by long evaporation times, heat from the surface is conducted through a liquid film and is dissipated by the evaporation at the liquid-gas interface. In the nucleate boiling regime, the vapor bubble production and the corresponding heat flux increase dramatically, thus decreasing the drop lifetime. The upper limit of the nucleate boiling regime, known as critical heat flux, corresponds to the maximum heat flux and the minimum drop lifetime. If the surface temperature is increased further, an insulating vapor layer develops beneath portions of the drop, leading to the film boiling or Leidenfrost regime, which is accompanied by reduced evaporation rates and an increased drop lifetime. For even greater surface temperatures, the drop remains 


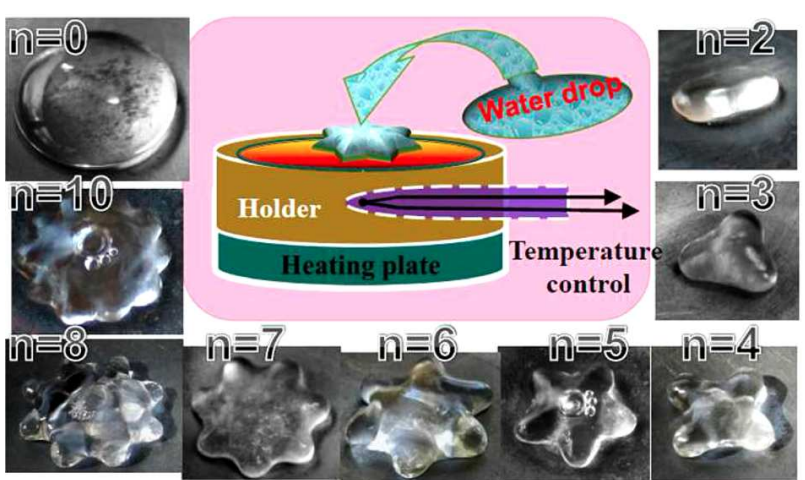

Fig. 1. Sketch of the experimental setup (inset) and examples of camera snapshots (top views) of a water drop, which exhibits a family of $n$-star equilibrium shapes evolving with increase in the time. $T_{s}=450{ }^{\circ} \mathrm{C}$

separated from the surface by a thin vapor layer, through which heat is conducted. The Leidenfrost effect leads to the appearance of a vapor layer on the surface of a heated solid sphere moving in a liquid, which can significantly reduce the hydrodynamic drag [11].

Among various mechanisms, which contribute to determining the shape of the drop, the current experimental evidence strongly supports the involvement of bubbles grown in the drop. The collapse of the cavitation bubble and the local Schlichting streaming field about the bubble may obviously underlie the shape patterns arisen in the drop.

Here, we report on the novel equilibrium shape patterns of Leidenfrost water drops locked in a shallow concave holder. While there have been significant efforts focused on shape perturbations of the liquid drop placed at a superheated surface, examples for flattening equilibrium shapes of the drop into higher than four dimensions [12] seem lacking so far. Multistar shapes with the number of stars $n$ varying between 11 and 2 have only been reported in the study of a symmetry-breaking instability, which occurs during the free evaporation of liquid nitrogen placed on a concave container initially at room temperature [13]. Utilizing our setup, we observe stationary multistar-shape patterns of water drops, referred to as "star-ordered water" (SOW), having dimensions up to eleven. We also capture the jumbled liquidand solid-like behaviors of water drops and hope for the experiments to follow will provide new unusual insights.

\section{Experimental}

A drop of distilled water (corresponding typically to less than $2 \mathrm{~cm}^{3}$ for the volume $\Omega$ ) is deposited in a spherical concave holder with curvature $R_{h}$ ranging from 20 to $120 \mathrm{~cm}$ and made in the center of a copper stage (Fig. 1). The stage is kept at a temperature $T_{s}$ varying from 200 to $650{ }^{\circ} \mathrm{C}$. Since the stage temperature is greater than the critical value for drop levitation, a cushion of vapor sets between the drop and the concave holder. Therefore, in our case of a locked drop, it can bounce back and forth in the concave holder getting deformed in the edge, when striking the concave curvature. It is therefore the drop itself that introduces the local time-deformation asymmetry in the response to the forward and backward sliding motions. As a consequence, the drop evaporates for as long as 6-10 min (drop lifetime $\tau$ ), by gradually evolving through a sequence of shapes exemplified in Fig. 1. In what follows, this will be discussed in a more rigorous way.

Movie clips and image snapshots are taken, by using a high-speed video camera. The multistar-shape patterns reported here have been observed for different liquids, including aqueous salt solutions, alcohol solutions, and oil dissolved in distilled water. In this work, we discuss the experimental results obtained with distilled water. The stage temperature and the concave form geometry have been found to be important issues regarding the occurrence or not of the shape patterns reported below.

\section{Results and Discussion}

We have obtained the data sets of drop volumes and shapes from many of our experiments. The results are summarized in Fig. 2 as a plot of the volume of a drop versus the time it levitates. Also shown is the shape evolution of the drop, which is characteristic of a particular value of $\Omega$. The latter illustrates the existence of a number of equilibrium shapes having a decreasing order of symmetry in the course of time. In Fig. 2, we introduce the Existence Time scale estimating the drop lifetime $\tau_{n}$, during which a balanced $n$-star equilibrium shape is observed.

Initially, the drop shape is described by a disk, which is filled with vapor bubbles and rotates with angular rate ranging from 5 to $15 \mathrm{~s}^{-1}$. With a span of time, the disk shape becomes secularly unstable to shape perturbations, leading to the SOW configura-

ISSN 2071-0194. Ukr. J. Phys. 2016. Vol. 61, No. 11 
tion with $n$ ranging from 9 to 11 (at time instants $t$ less than about $40 \mathrm{~s}$ in Fig. 2) with the values of $\tau_{n}$ as small as $1 \mathrm{~s}$. Next, these new drop branches gradually cease to exist, so that lower-star shapes are separated at $t$ ranging from 40 to about $230 \mathrm{~s}$, showing a pronounced increase in the lifetime with decreasing $n$. In this spirit, $\tau_{n}$ appears to vary from 2 to $20 \mathrm{~s}$ with the value of $n$ varying from 6 to 8 , whereas it changes from 15 to $60 \mathrm{~s}$ at $n$ ranging from 2 to 5 . After the multistar configuration with given $n$ is lost, the drop retains the disk-shape configuration for 1-20 s, which eventually evolves into another multistar configuration with a smaller value of $n$. Of particular interest here is the fact that the sequence of $n$ values depends on $\Omega, T_{s}$, and the concave holder geometry.

When the volume of the evaporating drop approaches $\approx 0.3 \mathrm{~cm}^{3}$, there is a very interesting effect in the dynamics of the levitating drop: it can behave itself like a piece of ice, by forming a motionless structure with unchanged volume (at $t$ ranging from $\approx 170$ to $330 \mathrm{~s}$ in Fig. 2). This freezing state can exist for about $1 \mathrm{~min}$, and then the dynamics is transformed again, when $\Omega$ rapidly scales down to a smaller value, finally allowing the water to evaporate in a sequence of freezing states (at $t$ greater than $\approx 330 \mathrm{~s}$ in Fig. 2 ).

In our experiments, there were three stable configurations of the freezing drop occurring at $\Omega=0.1$, 0.2 , and $0.3 \mathrm{~cm}^{3}$, which would be taken into account in developing the picture of the observed shape evolution. The literature known to us does not acknowledge this type behavior of levitating drops.

Obviously, the essential physics of the system is dictated by a competition of various phenomena. Thus, the development of multistar configurations is accompanied by decreasing the rotation rates followed by an abrupt pulsation of the drop, which is always produced just before the commencement of the multistar stable shape. This effect is likely related to the striking deformation of the drop edges discussed above.

Figure 3 depicts snapshots of the four- and six-star drop configurations captured on a $10-\mathrm{ms}$ time scale. It illustrates the evolution of the drop undergoing shape distortions due to the harmonic motion with pulsation at the frequency $\nu$ ranged from 25 to $35 \mathrm{~Hz}$ and a time dependence $\exp (-i \omega t)$ with $\omega=2 \pi \nu$. In this case, we can gather the insights of shape transformations of the $n$-star equilibrium shape. This unravels the changes in shape due to the water pulling from the outer periphery regions ( $\mathrm{P}$ in Fig. 3) in-

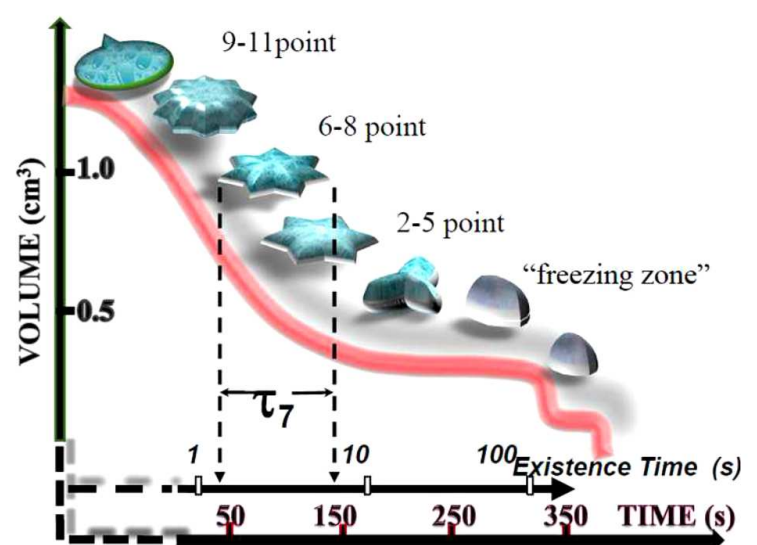

Fig. 2. Volume of a levitating drop versus the time at $T_{s}=$ $400{ }^{\circ} \mathrm{C}$ and typical shapes of the drop at various time instants with the scale Existence Time being the lifetime $\tau_{n}$ of the drop in the $n$-star equilibrium state

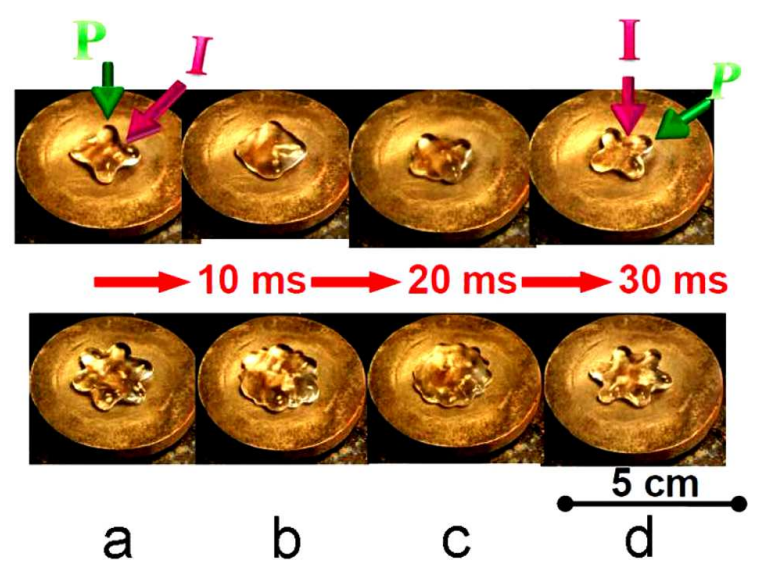

Fig. 3. Stages in the commencement of the four-star (upper snapshots) and six-star (lower snapshots) configurations on a ms time scale

ward and the accumulation in a core region of the drop. Concomitantly, the force exerted on the rest of the fluid points outward, by expelling the water from the interior regions ( $\mathrm{I}$ in Fig. 3) and, thereby, doubling $n$ in the intermediate state of the water pump process ( $b$ and $c$ in Fig. 3).

It is worth noting that if we keep $\Omega$ constant by carefully injecting more and more water into the drop, this results in unacceptably long $\tau_{n}$ of order of hours or more for shape patterns with $n$ smaller than six. An important aspect of this observation is that the value of $n$ strongly depends on the liquid viscosity and the drop volume. This fact offers opportunities to realize a sensing device measuring the 


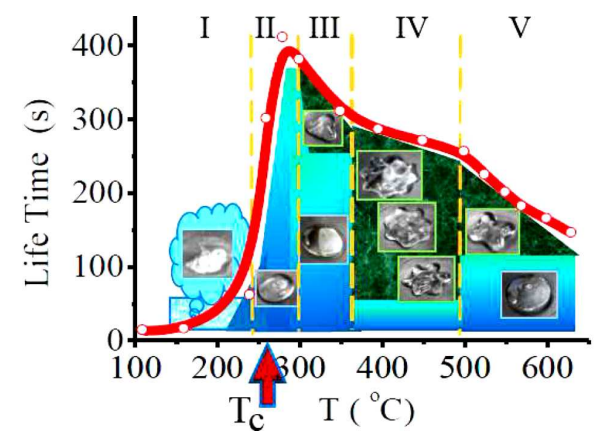

Fig. 4. Evaporation lifetime versus the substrate temperature taken for $\Omega=1 \mathrm{~cm}^{3}$. $T_{\mathrm{c}}$ is the critical temperature

viscosity and the concentration of particles in suspensions. The method is of particular relevance for biosensor systems, where the liquid drop maintains biological agents in a suspension.

For practical applications, it is, of course, highly desirable that the detection can be accomplished with the use of fast and robust techniques without requiring the use of post processing filter materials. Thus, a flow immunosensor, in which large volumes of bacterial suspensions in relatively low concentrations are filtered through an antibody coated membrane, has the attraction that it overrides the diffusion limitation and concentrates the bacteria on the filter prior to the assay $[14,15]$. One way to fulfill such a purpose and to exert a physical force that could deposit bacteria on an activated sensor surface is the exposure of a suspension of bacterial spores to an ultrasonic standing wave. Particles in a suspension experience the radiation forces that drive them toward pressure nodes or antinodes [16]. It is therefore anticipated that the inward and outward water flows illustrated in Fig. 3 may be of exciting relevance in optimizing the sensor performance. With this technique, a useful sensing principle can come from the fact that the deposition of biological agents on an activated sensor surface changes the concentration of particles in the suspension, thus concomitantly varying the number of stars $n$. Therefore, the use of SOW configurations appears to be essential for practical all-mechanical sensing devices unless and until the more sophisticated sensing principles are developed.

A common observation also requires measuring the evaporation time of a water drop with given initial volume over a range of surface temperatures to produce a drop evaporation curve, as shown in Fig. 4 for $\Omega=1 \mathrm{~cm}^{3}$. As water is warmed above $\approx 100{ }^{\circ} \mathrm{C}$ in the nucleate boiling region I of Fig. 4, the vapor bubbles become so abundant that they coalesce and violently churn upward, as schematically illustrated in the bottom image of region $\mathrm{I}$.

When the temperature is between 230 and about $280{ }^{\circ} \mathrm{C}\left(T_{\mathrm{c}}\right.$ in film boiling region II in Fig. 4$)$, each drop spreads in a thin layer (bottom image in region II), and the drop-stage boundary layer is covered with vapor. In this region, the energy is slowly transferred from the substrate to water above vapor by the radiation and the gradual conduction, by leading to reduced evaporation rates and the increased drop lifetime. As a consequence, a drop beads up and survives for more than six minutes. At even higher substrate temperatures, the water bead does not survive quite as long, by exhibiting a nearly linear evaporation lifetime decrease with increasing the temperature from about 280 to $350{ }^{\circ} \mathrm{C}$ (region III in Fig. 4). In this temperature interval, stationary SOW shape patterns are forced to exist on a short time scale of a few seconds, as exemplified by the top half and the bottom half images in region III in Fig. 4. The further increase in the temperature exhibits a more gradual decrease in the lifetime at temperatures ranging from $\approx 350$ to $500{ }^{\circ} \mathrm{C}$ (region IV in Fig. 4) with ability to maintain stationary shape patterns (imaged in region IV) for considerably longer times. The number $n$ in the SOW configuration gradually decreases upon evaporating the drop. At the further increase in the temperature in the range from 500 to $650{ }^{\circ} \mathrm{C}$, the evaporation lifetime decreases by about $40 \%$ (region $\mathrm{V}$ in Fig. 4), which is accompanied by an increase in the vapor bubble production rate and the correspondingly increased heat flux directed from the substrate to the drop. These turn out to decrease the drop lifetime, so that the SOW shape patterns, which are shown by the top half and the bottom half images in region $\mathrm{V}$, exist on a short time scale.

In order to interpret these experiments, we propose a mechanism based on the vapor breakups causing a short-time instability in the drop shape. As extensively reviewed, many macroscopic systems undergo transitions toward stationary inhomogeneous patterns, provided the system is externally maintained far from equilibrium [12]. Whatever its origin, the multiplicative shape disturbances can result in the breaking of the axial symmetry of a drop and are able, therefore, to induce stationary non-axisymmetric patterns in the drop. 
The pattern-forming scenario is schematically depicted in Fig. 5. If the concave curvature radius $R_{h}$ is large enough, the combined action of gravity, capillary (created by the surface tension of the curved drop surface), and reactive (created by vapor streams) forces can unlock drops pinned by substrate heterogeneities. This facilitates the directed motion of the drop in a global gradient, as shown in Fig. 5, a. Instead, at sufficiently small $R_{h}$ and $R_{d}<R_{h}$, the drop is locked in the bottom of a concave holder and, therefore, is immobile, by levitating in laminar vapor streams, which are brought to flow alongside of the drop (Fig. 5, b). In our experiments, this condition is satisfied for the drop volume $\Omega \leq 0.3 \mathrm{~cm}^{3}$ characteristic of the occurrence of the freezing zone in Fig. 2.

Increasing $\Omega$ leads $R_{d}$ to become greater than $R_{h}$, which produces a more interesting behavior of the vapor leakage from the shallow concave form. One subtle point is that, initially, the pressure-driven vapor phase cannot flow out of the interior between the substrate and the drop. Second, the density of an overheated compressed vapor gas (bunch under the drop area in Fig. 5, c) plays an important role in microfluidic gas flows, yielding the forced pulsations in vertical and horizontal directions, which cause, in turn, the levitated drop to rotate (arrows in Fig. 5, c). Third, it looks like a cushion of vapor breaks up the drop explosively; probably, as a result of the poking of gas fingers through the waterconcave interface. This breakup is thought to resemble the air inflation out of a balloon, which ultimately bursts. The consequently deformed water gives rise to basically the same pre-break up dynamics as Newtonian drops [17]: The drop flattens when water is driven to the center of the concave holder, and sheets of water are dragged backward to form lenticular shapes, as shown in Fig. 5, d. Similar multiply breakups tend to give multistar-shape patterns, as exemplified in Fig. 5, e, $f$ and observed experimentally in Figs. 1 and 3.

In this respect, the vapor-drop system considered here is supposed to be capable of the repeated delivery of vapor stripes in a pressure-driven gas flow in response to a continuously repetitive gas overheat (bunches under the drop areas in Fig. 5, $d-f$ ), when the drop shape is changed periodically by imposing the edge deformations of the drop. Therefore, we can consider the repetitive propagation of instanta-

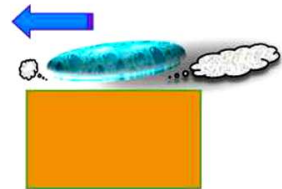

a

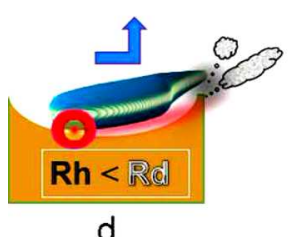

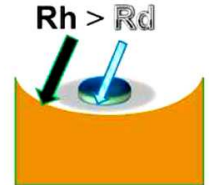

b

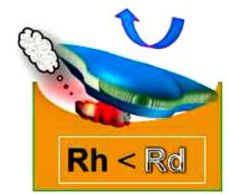

e

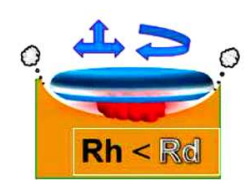

C

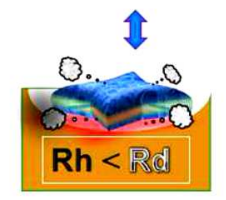

f
Fig. 5. Cartoon of the pattern-forming stages

neous edge disturbances of the drop, created by vapor breakups. The process ends up in a stationary $n$-star shape configuration driving the drop into the pulsating motional regime (Fig. 5, f). The stationary pattern is free to move only vertically, changing the water accumulation regions $\mathrm{P}$ and I shown in Fig. 3 slowly and periodically in time.

At sufficiently large $\Omega$, greater than $\approx 1.5 \mathrm{~cm}^{3}$, the drop is rotated about a vertical axis because of convective flows and slowly evaporating water, increasing the angular velocity with decreasing $\Omega$. At a given time, the vapor motion in a particular direction tends to decrease the surface energy in the nearby region of the drop due to the centrifugal force, thus causing small fluctuations in shape. As the drop curvature is also changed, the perturbed shape renders the drop shape unstable, giving rise to a new symmetric stationary shape pattern in a short period of time. Then the drop would cease rotating, but would undergo pulsations due to changes in the drop curvature and the surface energy across its surface. The pulsation amplitude decreases, as $\Omega$ decreases at the evaporation of a drop. As a consequence, the water drop again takes a rotating disk shape, which finally changes into the $n$-star configuration with a smaller value of $n$.

The exact physical scenario behind the shape evolution has yet to be understood. In this spirit, it has to be mentioned that, strictly speaking, spatially continuous extended media, such as fluids, are described by field variables obeying partial differential equations. A very common example is the reactiondiffusion equation,

$\frac{\partial \phi(\mathbf{r}, t)}{\partial t}=f(\phi)+D \nabla^{2} \phi$ 
where $\phi(\mathbf{r}, t)$ is a field that describes the state of the system at the spatial location $\mathbf{r}$ at time $t$, and, in general, $f$ is a set of nonlinear functions of all the variables.

A stationary pattern arises out of a disordered state via an instability at the zero frequency and a nonzero wave number. A simple model exhibiting such bifurcation is the Swift-Hohenberg equation [18, 19]

$\frac{\partial \phi}{\partial t}=a \phi-\phi^{3}-\left(\nabla^{2}+k_{0}^{2}\right)^{2} \phi+\xi(\mathbf{r}, t)$,

where $\xi(\mathbf{r}, t)$ stands for spatiotemporal fluctuations, $k_{0}$ is the stable wave number, and $a$ denotes a control parameter. In the absence of disturbances, this equation has a trivial homogeneous solution at $\phi=0$. This model exhibits a continuous transition from order to emerging patterns, when the above drop disturbances acting as the control parameter are increased.

Continuous shape transitions can also be induced by a different mechanism termed as the entropydriven phase transition, which relies on the long-term behavior of a local dynamics. This is, in part, due to the fact that, in the single-phase regime utilized here and characterized by long evaporation times, heat from the substrate is conducted through the liquid film and is dissipated by the evaporation at the liquidgas interface. The Gibbs free energy of a drop will be changed, when shape transformations are included in the system. The Gibbs free energy $(G)$ is split into a temperature-dependent term and a temperatureindependent term, using the enthalpy $(H)$ and the entropy $(S)$, respectively,

$\Delta G=\Delta H-T \Delta S$.

The entropy-driven mechanism can be explained from the stationary probability distribution of the system and does not involve any short-time instability [20]. A simple explanation is that the fluctuating noise is much more intense in the homogeneous or disordered phase $\phi=0$ than in an ordered region with $\phi \neq 0$. Then the noise drives the system far from $\phi=0$, and the spatial coupling fixes it at $\phi \neq 0$. An appropriate model can be given by the structure

$\frac{\partial \phi}{\partial t}=-\Gamma(\phi) \frac{\partial G}{\partial \phi}+\Gamma(\phi)^{1 / 2} \eta(\mathbf{r}, t)$,

which describes the relaxation dynamics with a freeenergy functional, where the kinetic coefficient $\Gamma(\phi)$ is field-dependent. A comprehensive study of this model has been given previously [21].

The above examples give a highlight on the most probable bridge to a more rigorous understanding of the multistar-shape patterns observed in this work.

\section{Conclusion}

In summary, we have observed the novel stationary multistar-shape patterns of Leidenfrost drops. We also report on the freezing-like behavior at superheated surfaces, when the drop evaporates in a sequence of freezing states. An important feature of the results is that they open exciting and useful possibilities of controlling the liquid-gas phase transitions at superheated surfaces. The method is particularly suitable for measuring the liquid viscosity and the concentration of particles in suspensions.

1. D. Bonn, J. Eggers, J. Indekeu, J. Meunier, E. Rolley. Wetting and spreading. Rev. Mod. Phys. 81, 739 (2009) [DOI: 10.1103/RevModPhys.81.739].

2. D.E. Sullivan, M.M. T. da Gama. in Fluid Interfacial Phenomena, edited by C.A. Croxton (Wiley, 1986), p. 45.

3. S. Chandrasekhar. The stability of a rotating liquid drop. Proc. R. Soc. London A 286, 1 (1965) [DOI: 10.1098/ rspa.1965.0127].

4. R.A. Brown, L.E. Scriven. The shape and stability of rotating liquid drops. Proc. R. Soc. London A 371, 331 (1980) [DOI: 10.1098/rspa.1980.0084].

5. K. Ohsaka, E.H. Trinh. Three-lobed shape bifurcation of rotating liquid drops. Phys. Rev. Lett. 84, 1700 (2000) [DOI: 10.1103/PhysRevLett.84.1700].

6. T. Tran, H.J.J. Staat, A. Prosperetti, C.Sun, D. Lohse. Drop impact on superheated surfaces. Phys. Rev. Lett. 108, 036101 (2012) [DOI: 10.1103/PhysRevLett.108.036101].

7. I.U. Vakarelski, N.A. Patankar, J.O. Marston, D.Y.C. Chan, S.T. Thoroddsen. Stabilization of Leidenfrost vapour layer by textured superhydrophobic surfaces. Nature (London) 489, 274 (2012) [DOI: 10.1038/ nature11418].

8. D.Quéré. Leidenfrost dynamics. Ann. Rev. Fluid Mech. 45, 197 (2013) [DOI: 10.1146/annurev-fluid-011212-140709].

9. A.-L. Biance, C. Clanet, D. Quéré. Leidenfrost drops. Phys. Fluids 15, 1632 (2003) [DOI: 10.1063/1.1572161].

10. J.D. Bernardin, I. Mudawar. The Leidenfrost point: Experimental study and assessment of existing models. J. Heat Transfer 121, 894 (1999) [DOI: 10.1115/1.2826080].

11. I.U. Vakarelski, J.O. Marston, D.Y.C. Chan, S.T. Thoroddsen. Drag reduction by Leidenfrost vapor layers. Phys. Rev. Lett. 106, 214501 (2011) [DOI: 10.1103/PhysRevLett.106.214501].

ISSN 2071-0194. Ukr. J. Phys. 2016. Vol. 61, No. 11 
12. T.G. Wang, E.H. Trinh, A.P. Croonquist, D.D. Elleman Shapes of rotating free drops: Spacelab experimental results. Phys. Rev. Lett. 56, 452 (1986) [DOI: 10.1103/PhysRevLett.56.452].

13. D.E. Strier, A.A. Duarte, H. Ferrari, G.B. Mindlin. Nitrogen stars: Morphogenesis of a liquid drop. Physica A 283, 261 (2000) [DOI: 10.1016/S0378-4371(00)00164-3].

14. S.S. Iqbal, M.W. Mayo, J.G. Bruno, B.V. Bronk, C.A. Batt, J.P. Chambers. A review of molecular recognition technologies for detection of biological threat agents. Biosens. Bioelectron. 15, 549 (2000) [DOI: 10.1016/S09565663(00)00108-1].

15. D. Ivnitski, I. Abdel-Hamid, P. Atanasov, E. Wilkins. Biosensors for detection of pathogenic bacteria. Biosens. Bioelectron. 14, 599 (1999) [DOI: 10.1016/S09565663(99)00039-1].

16. J.J. Hawkes, W.T. Coakley. Force field particle filter, combining ultrasound standing waves and laminar flow. Sens. Actuators B 75, 213 (2001) [DOI: 10.1016/S09254005(01)00553-6].

17. D.D. Joseph, J. Belanger, G.S. Beavers. Breakup of a liquid drop suddenly exposed to a high-speed airstream. Int. J. Multiphase Flow 25, 1263 (1999) [DOI: 10.1016/S03019322(99)00043-9].

18. J. Swift, P.C. Hohenberg. Hydrodynamic fluctuations at the convective instability. Phys. Rev. A 15, 319 (1977) [DOI: 10.1103/PhysRevA.15.319].

19. M.C. Cross, P.C. Hohenberg. Pattern formation outside of equilibrium. Rev. Mod. Phys. 65, 851 (1993) [DOI: 10.1103/RevModPhys.65.851].

20. M. Ibañes, J. García-Ojalvo, R. Toral, J.M. Sancho. Noise-induced scenario for inverted phase diagrams. Phys. Rev. Lett. 87, 020601 (2001) [DOI: 10.1103/PhysRevLett.87.020601]
21. J. Buceta, K. Lindenberg. Comprehensive study of phase transitions in relaxational systems with field-dependent coefficients. Phys. Rev. E 69, 011102 (2004) [DOI: 10.1103/PhysRevE.69.011102].

Received 12.04.16.

Translated from Ukrainian by O.I. Voitenko

Б. Романюк, В. Мельник,

В. Попов, О. Коротченков

СТАЦІОНАРНІ БАГАТОЗІРКОВІ

ФОРМИ КРАПЕЛЬ ВОДИ У ПРИСУТНОСТІ

ТЕМПЕРАТУРНОГО ГРАДІЄНТА

$\mathrm{P}$ е з ю м е

Еволюція форми крапель рідини, розташованій на перегрітій поверхні, є предметом численних досліджень протягом останніх десятиліть, оскільки вона має відношення до широкого спектра фізичних процесів, починаючи від поділу ядер до особливостей руху планет, і реалізується в багатьох промислових процесах. В роботі показано, що крапля рідини, замкнена у сферичній щілині, здатна набувати багатозіркову форму із незвично великою кількістю зірок $n$, більшою за одинадцять. Отримані результати пояснюються в термінах багаторазового збурення форми краплі парою, утвореною у проміжку крапля-щілина, що час від часу проривається назовні. Цей процес супроводжується пульсуючими рухами краплі і появою стаціонарних $n$-зіркових конфігурацій. Також спостережено заморожування краплі, коли її випаровування відбувається у послідовності заморожених станів все меншого об'єму. Ці результати можуть знайти застосування для контролю фазових переходів рідинагаз на перегрітих поверхнях і можуть бути використані для вимірювання в'язкості і концентрації частинок в суспензії. 